\title{
Resenha
}

Debates sobre a adolescência contemporânea e o laço social

Gurski, R.; Rosa, M. D.; Poli, M. C. (Orgs.)

Curitiba: Juruá, 2014, 204 p.

\section{DEBATES SOBRE A ADOLESCÊNCIA CONTEMPORÂNEA E O LAÇO SOCIAL}

\author{
Juliana Falcão Barbosa \\ Charles Elias Lans
}

DOl: http//dx.doi.org/10.11606/issn. 1981-1624.v20i1p339-345.

A

coletânea organizada por Rose Gurski, Miriam Debieux Rosa e Maria Cristina Poli, Debates sobre a adolescência contemporânea e o laço social, apresenta debates, questionamentos e reflexões acerca dos modos de viver a adolescência contemporânea e discussões sobre o laço social em nossa época.

A pergunta que norteia o livro aparece na apresentação: "Como $\mathrm{o}$ adolescente contemporâneo vive essa passagem frente às configurações do laço social atual? Se a grande questão de todo sujeito humano, e mais ainda, do sujeito adolescente, é encontrar modos de se representar no discurso social, nos perguntamos, como o jovem de hoje faz para se representar?" (p. 8).

O livro compila dez artigos de diferentes autores implicados no trabalho com adolescentes na clínica e em outros espaços, tais como instituições e projetos sociais, em que, ainda assim, se faz clínica. Publicar um livro em formato de compilação não é tarefa fácil, já que não basta juntar textos acerca de uma mesma temática para que essa fórmula funcione. Uma compilação, para que funcione como

- Psicóloga da Secretaria de Estado da Criança do Distrito Federal e mestre em Psicologia pela Universidade Federal de Alagoas, Maceió, AL, Brasil.

- - Professor Associado do Instituto de Psicologia da Universidade Federal de Alagoas, Maceió, AL, Brasil. 
livro, precisa apresentar autores que se guiem pela mesma ética em seu trabalho. Este é um ponto que fica claro em todos os textos da coletânea: a coesão acerca da ética que pauta o trabalho de cada autor com os sujeitos adolescentes, em seus diferentes espaços.

Como em quase toda coletânea, é possível ler cada texto separadamente, em qualquer ordem. No entanto, ao ler o livro de forma contínua, deparamo-nos também com fios que interligam os trabalhos. Ao mesmo tempo em que podemos lê-lo despretensiosamente como um mergulho prazeroso nas diferentes nuances do universo adolescente, ele pode ser lido também como matéria de estudo, pela sua consistência teórica e clínica. Enquanto matéria de estudo, percebemos que há uma coerência sistematizável, dentre os muitos temas que os autores abordam. E é nessa possibilidade sistematizável que destacamos alguns eixos que julgamos unirem os dez artigos.

Outeiral (2005), em seu livro Clínica psicanalítica de crianças e adolescentes, pontua que, em mais de 30 anos de clínica, testemunhou intensas modificações ocorridas neste período. O primeiro apontamento que ele faz é sobre os problemas derivados da violência em suas diferentes formas. Em Debates sobre a adolescência contemporânea e o laço social é possível verificar que os textos seguem a linha desse ponto destacado por Outeiral.

Poderíamos dizer que a violência é o primeiro e grande eixo, o fio condutor deste livro, o eixo que consegue ligar praticamente todos os trabalhos, cada um com a sua especificidade. No entanto, existem ainda outros três eixos que fazem com que os artigos reunidos dialoguem.

O segundo eixo diz respeito à questão geracional. Sabemos que o sujeito se constrói por meio da relação com o outro. A isso, Lacan identificou como operações de alienação e separação. Os autores dão relevo à questão da herança simbólica entre as gerações ao afirmarem que a herança recebida de seus pais, avós e bisavós, influencia a história de vida do adolescente, suas possibilidades no futuro e a construção de sua subjetividade.

O terceiro eixo que identificamos no livro é acerca do neoliberalismo e do capitalismo na contemporaneidade. Os sintomas e as psicopatologias adolescentes podem ser considerados um sintoma social na medida em que falam sobre algo que acontece em determinada época. $\mathrm{O}$ adolescente, por estar ingressando no meio social, defrontase com aspectos da cultura que nós, adultos, já vivenciamos demais e estamos perto demais - há muito mais tempo - para perceber. 
O quarto eixo que podemos identificar é a função do ato na adolescência, que pode aparecer em forma de passagens ao ato, atos performativos, atos simbólicos. Um ato é algo que marca uma posição, ou ainda, uma mudança de posição subjetiva.

\section{Primeiro eixo - a violência}

No artigo de Miriam Debieux Rosa e Maria Cristina Vincentin, intitulado "Os intratáveis: O exílio dos adolescentes do laço social pelas noções de periculosidade e irrecuperabilidade", temos discutidas questões acerca das estratégias de patologização da juventude, especialmente da juventude pobre. As autoras se fundamentam na Psicanálise e na análise institucional, para abordar os diagnósticos que costumam ser atribuídos aos adolescentes imersos na violência, como o de personalidade antissocial. Tais diagnósticos, pautados por uma ética médica e/ ou jurídica, acabam taxando os adolescentes como perigosos ou irrecuperáveis.

As autoras trazem uma reflexão intensa sobre como são tratados os adolescentes em conflito com a lei. A discussão é importante visto que continua permeando, em círculos diversos, a questão da redução da maioridade penal. Elas enfatizam que, em relação à violência praticada pelos jovens, existe um lado que geralmente fica negligenciado: a violência a que os jovens são expostos. "Ler o discurso sobre a violência no seu avesso significa inverter o enunciado do imaginário social” (p. 55). Assim, poderíamos ler “jovens são violentados” onde se escreve "jovens são violentos".

O artigo de Olivier Douville, "Crianças e adolescentes na guerra e sua relação com a ancestralidade", apresenta uma problemática bem específica. O texto é uma síntese de oito anos de trabalho clínico com crianças e adolescentes inseridos em situações de guerra. $\mathrm{O}$ autor identifica essas crianças e adolescentes como "portadores da morte" ou como sujeitos ameaçados, o que podemos identificar como análogo à inversão do enunciado proposta por Rosa e Vincentin.

Ainda analogamente ao que Rosa e Vincentin alertam sobre os perigos dos diagnósticos atribuídos aos adolescentes na violência, Douville também alerta para uma supervalorização dos diagnósticos e a redução da clínica a uma perícia. "Muitos programas humanitários tomam como tarefa a medida dos graus de trauma com ferramentas 
objetivantes inspiradas nesta noção de TEPT, o que limita muito uma apreensão psicodinâmica da evolução desses jovens nos contextos familiar, cultural e social" (p. 138).

\section{Segundo eixo - $a$ questão geracional}

O artigo de Serge Lesourd, "Adolescentes difíceis ou dificuldades da cultura?", aborda diversas questões acerca da adolescência e, já no início, nos apresenta uma proposição que é emblemática no que se refere ao eixo que pretendemos assinalar aqui: "O Édipo se dá, não apenas na diferença dos sexos, mas na diferença das gerações” (p. 19). Lesourd interroga, ao longo de seu texto, os efeitos da diferença de gerações em outro momento da história em contraponto aos efeitos que encontramos atualmente. "Pais e educadores colocam em pauta o comportamento adolescente de oposição ao adulto, de contestação de suas decisões, ou mesmo de ato de violência.... A diferença de geração, que preservava os adultos desses ataques entre pares, não mais impõe limite" (p. 21).

Olivier Douville, em seu artigo sobre as crianças e adolescentes na guerra, também discorre sobre a questão geracional. No entanto, em sua experiência com esses sujeitos que haviam lutado em conflitos, havia também uma espécie de inversão. Ao invés de confrontar seus pais e avós, o propósito da guerra era o de vingar os antepassados, de proteger a sua imagem.

\section{Terceiro eixo - Promessas do neoliberalismo e do capitalismo}

Roséli Maria Olabarriaga Cabistani fala sobre a falta e, consequentemente, o desejo. Seu artigo, "Formulações sobre o desejo e a economia da angústia na adolescência", propõe uma interlocução entre a psicanálise e a educação. Ela se utiliza do documentário Pro dia nascerfeliz.(Jardim, 2006) para abordar a questão do desejo entre os jovens, assim como a angústia decorrente das incertezas contemporâneas. "A noção de falta é então um ponto nodal da teoria psicanalítica, uma vez que é pela inscrição da falta no desejo da mãe e depois do pai, que o sujeito torna-se um ser desejante" (p. 60).

Seguindo numa linha semelhante, Rose Gurski aborda os efeitos que a modernidade e o capitalismo têm no laço social atual, também evocando a questão da falta. Em seu artigo, "Massacres juvenis e a paixão pelo Real: o império do sentido e a discussão sobre os impasses do adolescer na atualidade", Gurski propõe que os massacres juvenis são um sintoma do laço social atual. A partir do caso de Cho Seung-hui que, em 2007, 
protagonizou um dos maiores massacres juvenis nos EUA, a autora se questiona sobre o que estes jovens devolvem através dos atos de violência. Gurski parte da Psicanálise e vai além, apresentando discussões em torno das noções de experiência e transmissão, de Walter Benjamin, e da ideia de "paixão pelo real", proposta por Slavoj Zizek.

A autora, citando Debord, menciona que em nossa sociedade imperam as modernas condições de produção, em que há uma intensa acumulação de espetáculos. Para Gurski, "Modernidade e ciência andam juntas. Se os novos modos de produção levam o sujeito a consumir seu corpo no labor, a promessa da ciência de tentar resolver a dissimetria entre sujeito e objeto não oferece saídas mais criativas para o drama humano da falta" (p. 107).

O artigo "Adolescência e violência: a criação de dispositivos clínicos no território conflagrado das periferias", de Jorge Broide, traz experiências de trabalho com jovens em situação de vulnerabilidade. Partindo da Psicanálise e atuando nas políticas públicas voltadas a jovens vulneráveis e em conflito com a lei, o autor salienta a necessidade de uma maior inserção da Psicanálise no campo social através da ampliação de diferentes dispositivos clínicos nos territórios mais vulneráveis. "É essa relação com os produtos que, segundo Milton Santos, fragmenta o território e a relação entre as pessoas. O que era conhecido não é mais reconhecido e a força do produto que imaginariamente traz a possibilidade de ser sujeito afeta o laço social" (p. 126).

Maria Celina Peixoto Lima propõe, em "O declínio do mestre e suas relações com o saber na adolescência: novas reflexões sobre a psicologia do escolar", que o sintoma adolescente atual seria um estado de pane diante da demanda escolar. A autora discute sobre a queda dos ideais, a dessacralização da escola e a desvalorização dos professores, que tem levado os adolescentes a um modo de identificação horizontal, imaginária, à formação de bandos. "O que a pós-modernidade potencializa é a desconstrução da ordem fálica organizada na ideia de uma referência unificante para decliná-la em referências múltiplas” (p. 163).

\section{Quarto eixo - a função do ato na adolescência}

Retomamos uma citação de Rosa e Vincentin para definir mais precisamente o que concebemos como ato neste eixo: "Há atos que 
cifram o discurso, ainda que sem palavras, quando o atuar estabelece vínculos e permite o encadeamento associativo. $\mathrm{O}$ ato cria uma cena no real que encena o desejo e abre a possibilidade de ser falado pelo Outro. Trata-se de um apelo de reconhecimento" (p. 46).

O artigo de Ana Maria Costa e Maria Cristina Poli fala particularmente sobre a questão do ato na adolescência. O texto, intitulado "Sexuação na adolescência: um ato performativo", aborda a noção psicanalítica de sexuação, identificando-a como um ato performativo. Elas realizam uma discussão acerca das escolhas de objeto e da identificação sexual, questão central na clínica com adolescentes. O texto apresenta avanços em alguns dos impasses teóricos que o tema da sexuação na adolescência enfrentou ao longo da história da Psicanálise. "Nesse tempo da constituição do sujeito, a adolescência trata-se do tempo de um ato, a iniciação sexual, e de uma tomada de posição na referência sexuada" (p. 74).

Seguindo no caminho da sexuação adolescente, Laurence Gavarini também aborda esta questão em seu texto intitulado "Como os adolescentes das periferias (se) contam? Um jogo endereçado aos pesquisadores". Ali ela apresenta os resultados de uma pesquisa na clínica do social, desenvolvida na França, sobre a construção identitária adolescente. Dois pontos abordados nessa construção são as referências de gênero e intergeracionais.

Pensando no ato como algo que muda a posição do sujeito no discurso, podemos identificar formulações neste sentido no texto de Anna Carolina Lo Bianco e Fernanda Costa-Moura. "Escrever nas coisas: a utopia contemporânea na linguagem dos adolescentes" aborda as pichações de rua feitas por adolescentes. As autoras se baseiam em análises de Walter Benjamin para discutir os efeitos subjetivos das transformações no discurso. As pichações possuem uma discursividade própria e funcionam como uma espécie de subversão do funcionamento da linguagem. Elas frisam que o grafite "Priva a palavra de seu uso (como mercadoria usada para trocas) e a insere numa ordem em que, estando livre da prisão de ser útil, a palavra pode existir como puro ato (escritura expressiva) aposto nos muros da cidade" (p. 97. Grifo das autoras).

Se continuarmos pela via da inscrição e retomarmos o artigo de Gurski, identificamos nos assassinatos em massa também um ato que pode ser nomeado como performativo. A autora interroga "Por que alguém tão anônimo buscou um modo de escrever seu nome em letras de todos os tipos ao redor do planeta?... O que será que esses

344 Estilos clin., São Paulo, v. 20, n. 2, mai./ago. 2015, 339-345. 
jovens devolvem com seus atos? Por que não podem escrever seus nomes, fazer suas marcas de outro modo?" (p. 104).

Isso nos leva de volta ao eixo que une os textos que compõem a coletânea: a violência. Nos massacres juvenis, a violência aparece no real, da forma crua. No entanto, o que vimos ao longo do livro, foram as diversas formas de violência produzidas e sofridas pelos jovens, como, por exemplo, a violência praticada pelos adolescentes infratores, violência da guerra e violência das categorizações e diagnósticos que não abrem espaço para a subjetividade.

$\mathrm{O}$ que os profissionais reunidos neste livro fazem, em seus diferentes modos de trabalhar com os adolescentes, está pautado pela ética psicanalítica de valorizar a palavra e possibilitar um espaço de escuta do inconsciente. Outeiral (2005) salienta que o ofício do psicanalista é muito solitário, o que pode produzir um estado de tensão interna. Escrever e publicar, colocar para fora e buscar ouvintes (e leitores) e interlocutores, torna menos solitária a tarefa. O leitor que se aventura na escuta aos adolescentes certamente encontrará neste livro uma leitura estimulante.

\section{REFERÊNCIAS}

Outeiral, J. (Org.). (2005). Clinica psicanalitica de crianças e adolescentes: desenvolvimento, psicopatologia e tratamento. (2a ed.). Rio de Janeiro, RJ: Revinter. charles.lang@ip.ufal.br juliana.falcao@gmail.com Rua Sandoval Arroxelas, 480/201 54035-300 - Maceió - AL - Brasil.

Recebido em dezembro/2014. Aceito em maio/2015. 